\title{
The effect of the diversified signal of melatonin on milk yields in seasonally breeding sheep
}

\author{
Edyta Molik', Marta Pasternak³, Michal Błasiak1, Tomasz Misztal², Katarzyna \\ Romanowicz ${ }^{2}$ and Dorota Zieba'
}

${ }^{1}$ Agricultural University in Krakow, Department of Swine and Small Ruminants Breeding, Biotechnology and Genomics Laboratory, Krakow, Poland, ${ }^{2}$ The Kielanowski Institute of Animal Physiology and Nutrition, Polish Academy of Sciences, Department of Endocrinology, Jablonna, Poland, ${ }^{3}$ National Research Institute of Animal Production, Department of Animal Genetic Resources Conservation, Balice, Poland

\begin{abstract}
Previous studies demonstrated that milk yields in sheep displaying strong seasonal sexual activity depend on the day length. The objective of the studies was to determine whether the introduction of melatonin in high pregnancy affects milk secretion in seasonally sheep. The studies were carried out on 60 Polish Longwool sheep. Sheep were allocated to three groups: Group I ( $\mathrm{n}=20$ - the control group, lambed in February), Group II ( $\mathrm{n}=20$ - a group of sheep lambed in June and kept under natural day-length conditions), Group III ( $\mathrm{n}=20$ - a group of sheep with melatonin implants injected six weeks before lambing, sheep lambed in June). Lambs were reared with mothers up to 56 th day of their life. When lambs were weaned, ewes were milked mechanically twice a day up to the dry period. Once a month collective milk samples were drawn from six sheep from each group in order to determine the concentration of melatonin. Milk yields were subjected to individual checks every 10 days. The studies demonstrated that sheep lambed in February (Group I) displayed the highest milk yields in the milking period $(37.8 \pm 8.1 \mathrm{l})$. The milk performance of the two other groups was lower and amounted to $30.2 \pm 9.4$ litres in case of sheep lambed in June and to $29.2 \pm 7.6$ litres in sheep with melatonin implants. The introduction of melatonin signal to produce a short-day condition in state of high pregnancy in ewes caused a drop of milk yields both in the period of lambs raising and during milking.
\end{abstract}

Archiv Tierzucht 56 (2013) 93, 924-932

doi: 10.7482/0003-9438-56-093

Corresponding author:

Edyta Molik; email: rzmolik@cyf-kr.edu.pl

Biotechnology and Genomics Laboratory, Department of Swine and Small Ruminants Breeding, Agricultural University in Krakow, 30-059 Krakow, Poland

() 2013 by the authors; licensee Leibniz Institute for Farm Animal Biology (FBN), Dummerstorf, Germany. This is an Open Access article distributed under the terms and conditions of the Creative Commons Attribution 3.0 License (http://creativecommons.org/licenses/by/3.0/). 
Keywords: sheep, day length, melatonin, milk yield

Abbreviations: d: days, G: group, MLT: melatonin

\section{Introduction}

Sheep are animals displaying very clear features of seasonal breeding. The dependence of reproduction on the season of the year is attributable to the organism sensitivity to changes in secretion of melatonin (MLT) from the pineal gland (Reiter 1991). Melatonin is synthesized and released at night, whereas at day time the secretive activity of the pineal gland is reduced (Arendt et al. 1988). Until now it was believed that milk yields in mammals are affected by genetic and environmental factors. In recent years, though, a special focus has been placed on light, being the modulator of the prolactin concentration. In farm animals changes of the light day play a very important role as they determine their yields. The introduction of e.g. long photoperiod in hens enhanced egg-laying, whereas in cows it produced a higher concentration of prolactin and increased milk yields (Peters et al. 1978, Reksen et al. 1999, Dahl et al. 2000, Morrissey et al. 2008). The photoperiod is of special importance in shortday animals, in which the day length involves changes of MLT concentrations (Karsch et al. 1984). In the autumn and winter (short-day period) higher concentrations of MLT are produced, whereas in the spring and summer the secretion of MLT decreases. Changes in the secretion of MLT affect the secretion profile of prolactin which is responsible for entering and maintenance of lactation. In the short-day period the increased secretion of MLT contributes to a decrease of prolactin secretion, and in the spring and summer period the short signal of MLT does not inhibit the synthesis of prolactin (Lincoln et al. 2003). Changes in MLT secretion throughout the year modulate the secretion profile of prolactin and have an effect on sheep's milk yields. Studies carried out by Molik et al. $(2006,2011)$ on lactating sheep showed that sheep entering lactation in the period of shorter days produced a yield of milk which was lower by $50 \%$ compared to sheep milked in the long-day period. The shorter of days caused an increase of MLT concentration and a decrease of prolactin levels, which contributed to the reduced synthesis of milk in sheep. In studies performed by Molik et al. (2009) an attempt was made to maintain lactation in sheep lambed in June and milked in the period of shortened days by using artificial long-day conditions (16L:8D). In these sheep the length of lactation and the amount of obtained milk was similar to yields of sheep lambed in the same period (June) and kept under natural day-length conditions. Seasonal changes in MLT secretion have a significant effect on milk-performance parameters of sheep, and because of that, by determining physiological factors which are required for milk synthesis in seasonally breeding sheep, it is possible to control the period of using them for dairy production. It is probable that such a discovery can contribute to maintaining milk yields of sheep on a profitable level in the period of shorter days, in particular now when consumers expect healthy, ecological and harmless food, to which undoubtedly sheep milk belongs.

Therefore, the objective of the studies was to verify whether the introduction of exogenous MLT during the stage of a high pregnancy affects milk secretion in sheep. 


\section{Material and methods}

\section{Animals}

The study was carried out at the Experimental Station of the Department of Swine and Small Ruminant Breeding of the Agricultural University of Krakow, Poland. Polish Longwool ewes $(n=60)$ were used for the experiment. This breed exhibits strongly seasonal reproductive activity. The animals were four to five years old and weighed $60 \pm 5 \mathrm{~kg}$. Prior to the beginning of the experiment, all animals were housed in individual pens under natural photoperiodic and thermoperiodic conditions (longitude: $19^{\circ} 57^{\prime} \mathrm{E}$, latitude: $50^{\circ} 04^{\prime} \mathrm{N}$ ) and had a body condition score (BCS) of 3 (on a scale from 0 to 5 , where $0=$ emaciated and $5=$ obese by Russel et al. 1969).

\section{Dietary treatments}

Throughout the experiment, sheep were fed according to their physiological status. From the mating to the end of the fourth month of pregnancy, sheep were fed in conformity with the standards of the National Research Institute of Animal Production (Norms 1993) based on: silage (dry matter $273 \mathrm{~g} / \mathrm{kg}, 41 \mathrm{~g}$ of crude protein per $\mathrm{kg}, 1.53 \mathrm{MJ}$ of net energy) and hay (dry matter $860 \mathrm{~g} / \mathrm{kg}, 118 \mathrm{~g}$ of crude protein per $\mathrm{kg}, 3.83 \mathrm{MJ}$ of net energy) (sheep lambing in February - Group [G] I) and forage pasture (dry matter $235 \mathrm{~g} / \mathrm{kg}, 50 \mathrm{~g}$ of crude protein per $\mathrm{kg}$, $1.36 \mathrm{MJ}$ of net energy) sheep lambing in June (G II and G III).

In order to unify feeding from the fifth month of pregnancy to the dry period, all sheep ( $\mathrm{G} \mathrm{I}, \mathrm{G}$ II, G III) received $1.5 \mathrm{~kg}$ of pelleted concentrate (7.5 MJ of net energy and $220 \mathrm{~g}$ of crude protein per $\mathrm{kg}$ of concentrate) and supplemental hay (dry matter $860 \mathrm{~g} / \mathrm{kg}, 118 \mathrm{~g}$ of crude protein per kg, 3.83 MJ of net energy) for standardization (Norms 1993). All animals had free access to water and mineral licks.

\section{Experimental design}

The ewes were randomly allocated to three groups, with 20 animals per group. Oestrus synchronization was carried out with gestagens using the Chronogest method. Polyurethane sponges impregnated with $40 \mathrm{mg}$ Cronolone (Intervet, Boxmeer, The Netherlands) were inserted in sheep intravaginally for $14 \mathrm{~d}$ and removed at the time of 500 I.U. PMSG injections (Serogonadotropin, Biowet, Drwalew, Poland). Oestrus occurred within 48-72 h of PMSG administration, and the duration of oestrus was additionally controlled using a teaser ram. Mating after oestrus synchronization was performed on 5 September for $\mathrm{G} I$ and on 15 January for G II and G III. Polish Longwool rams weighing $80 \pm 5 \mathrm{~kg}$ were used for natural mating. Ewes of G I lambed between 20-25 February and those of G II and III lambed between 18-24 June. Sheep of the third group were inserted exogenous MLT six weeks before lambing. Subcutaneous MLT implants (18 mg of exogenous MLT; Melovine, Ceva Animal, Libourne, France) were inserted into each ewe in G III at 90 -day intervals ( $18 \mathrm{mg}$ of exogenous MLT shows a biological activity for a period of $90 \mathrm{~d}$ ). Experimental ewes reared twins and the mean prolificacy was $190-200 \%$. The mean body weight of lambs was $2.6 \mathrm{~kg}$ and a losses was $1 \%$. Parturitions were not complicated and the veterinary help was not needed. Lambs stayed with their mothers until $56 \mathrm{~d}$ of age, afterwards they were weaned and ewes were used for 
milking. When the lambs were reared, the milk production of the ewes was estimated based on the lambs' weight gain from 2 to $28 \mathrm{~d}$ of age using a conversion factor of 4.5 litres of milk per kg of weight gain. During the milking period, ewes were milked twice a day using an Alfa-Laval milking machine. Milk yields were recorded individually at 10-day intervals. For each ewe the dry period was defined as beginning when the milk yield was less than $50 \mathrm{ml}$ per day.

From day 57 of lactation until the dry period, blood was drawn from each ewe every $28 \mathrm{~d}$ to monitor the changes in MLT concentrations. On each sampling date, $5 \mathrm{ml}$ blood samples were collected at $20 \mathrm{~min}$ intervals over a period of $6 \mathrm{~h}$ beginning at 12:00. The whole blood was sampled using a catheter, which was inserted into the jugular vein $6 \mathrm{~h}$ prior to the blood collection program. After centrifugation in heparinized tubes, plasma was stored at $-20^{\circ} \mathrm{C}$ until hormone assays were performed. Blood sampling methodology was based on previous studies (Molik et al. 2007, 2010, 2011, 2013).

Melatonin was assayed in unextracted plasma according to the method of Fraser et al. (1983), modified by Misztal et al. (1996). Ovine anti-melatonin serum (AB/S/01, Stockgrand Ltd., Guildford, UK), synthetic MLT (Sigma-Aldrich, St. Louis, MI, USA) as a standard and [O-methyl-3H]-melatonin (Amersham, Amersham, UK) as a tracer were used. Melatonin free plasma for calibrated curve and blanks was obtained by early afternoon bleeds from sheep and striped from endogenous MLT by activated charcoal Norit-A (Sigma-Aldrich, St. Louis, MI, USA). The range of the calibrated curve was from 15.6 to $1000 \mathrm{pg} / \mathrm{mL}$ and the working dilution of antibodies was 1:4000. Bound and free tracers were separated after overnight incubation at $4^{\circ} \mathrm{C}$ by dextran-coated charcoal. Sensitivity of the assay was $16.8 \pm 8.0 \mathrm{pg} / \mathrm{ml}$ and the intra- and inter-assay coefficients of variations were 10.5 and $13.2 \%$, respectively.

\section{Statistical analysis}

The milk-performance parameters (milk yield during the first $28 \mathrm{~d}$ of lactation, duration of lactation, $\mathrm{d}$ of milking and milk production) were expressed as the means \pm SEM (standard error of mean). The Mann-Whitney test was used to assess the differences among groups in lactation parameters. Plasma MLT concentrations are expressed as the mean \pm SEM. The effects of the treatments on plasma hormone concentrations were analysed using a oneway analysis of variance (ANOVA), followed by the post-hoc least significant difference test using SAS software (SAS Institute Inc., Cary, NC, USA). The differences in lactation parameters between groups were assayed by the nonparametric ANOVA rank Kruskal-Wallis test using the same SAS software.

\section{Results}

\section{Lactation parameters}

In the first $28 \mathrm{~d}$ of lactation milk yields of $\mathrm{G} I$ and $\mathrm{G}$ II sheep were significantly highest $(P \leq 0.01)$ reaching the level of $63.2 \pm 13.9$ and $61.8 \pm 11.2$ litres. The lowest milk yields were observed in G III sheep amounting to $44.6 \pm 11.4$ litres (Table 1). The obtained results of the studies demonstrated that $\mathrm{G} I$ sheep had the longest lactation period of $172 \pm 18.3 \mathrm{~d}$. Lactation of $\mathrm{G}$ II sheep was significantly shortest $(P \leq 0.01)$ and lasted $136 \pm 10.4 \mathrm{~d}$. The significantly greatest 
milking persistency $(P \leq 0.05)$ lasting $117 \pm 17.4 \mathrm{~d}$ was observed in sheep of $\mathrm{G}$ I. Sheep of G II and sheep with MLT implants were milked for the shortest periods $(80 \pm 9.8$ and $95 \pm 10.4 \mathrm{~d}$ respectively) and identified differences were statistically significant $(P \leq 0,05)$ in relation to the control G.

Table 1

Parameters characterizing lactation duration and its efficiency of Polish Longwool sheep kept under natural lighting conditions (Group I, II), sheep with exogenous melatonin implants (Group III)

\begin{tabular}{lccr}
\hline Groups/parameters of lactation & Group I & Group II & Group III \\
\hline Milk yield of the first 28 days of lactation & $63.2^{\mathrm{A}} \pm 13.9$ & $61.8^{\mathrm{A}} \pm 11.2$ & $47.6^{\mathrm{B}} \pm 10.9$ \\
Total length of lactation, days & $171^{\mathrm{Aa}} \pm 18.3$ & $136^{\mathrm{B}} \pm 10.4$ & $147^{\mathrm{b}} \pm 12.1$ \\
Days of milking, days & $117^{\mathrm{a}} \pm 17.4$ & $80^{\mathrm{b}} \pm 9.8$ & $95^{\mathrm{b}} \pm 10.4$ \\
Milk production during milking, liters & $37.8^{\mathrm{a}} \pm 8.1$ & $30.2^{\mathrm{b}} \pm 9.4$ & $29.2^{\mathrm{b}} \pm 57.6$ \\
\hline
\end{tabular}

Table 2

Individual control (intervals 10 days) milk yield parameters of Polish Longwool sheep kept under natural lighting conditions (Group I, II), sheep with exogenous melatonin implants (Group III)

\begin{tabular}{lccc}
\hline $\begin{array}{l}\text { Milking Yield- } \\
\text { (intervals for 10 days ) }\end{array}$ & Group I & Group II & Group III \\
\hline 1st control milk & $0.48^{\mathrm{a}} \pm 0.018$ & $0.42^{\mathrm{b}} \pm 0.008$ & $0.43^{\mathrm{b}} \pm 0.013$ \\
2nd & $0.45^{\mathrm{a}} \pm 0.017$ & $0.40^{\mathrm{b}} \pm 0.016$ & $0.33^{\mathrm{b}} \pm 0.009$ \\
3rd & $0.50^{\mathrm{a} . \mathrm{A}} \pm 0.012$ & $0.38^{\mathrm{b}} \pm 0.012$ & $0.28^{\mathrm{B}} \pm 0.001$ \\
4th & $0.45^{\mathrm{A} . \mathrm{a}} \pm 0.011$ & $0.35^{\mathrm{b}} \pm 0.015$ & $0.26^{\mathrm{B}} \pm 0.001$ \\
5th & $0.37^{\mathrm{a} \cdot \mathrm{b}} \pm 0.012$ & $0.30^{\mathrm{b}} \pm 0.001$ & $0.23^{\mathrm{b}} \pm 0.015$ \\
6th & $0.35^{\mathrm{A}} \pm 0.001$ & $0.21^{ \pm} \pm 0.006$ & $0.18^{\mathrm{B}} \pm 0.013$ \\
7th & $0.37^{\mathrm{A}} \pm 0.006$ & $0.18^{\mathrm{B}} \pm 0.001$ & $0.14^{\mathrm{B}} \pm 0.012$ \\
8th & $0.26^{\mathrm{A} \cdot \mathrm{a}} \pm 0.006$ & $0.15^{\mathrm{b}} \pm 0.002$ & $0.07^{\mathrm{B}} \pm 0.009$ \\
9th & $0.20^{\mathrm{A}} \pm 0.009$ & $0.02^{\mathrm{B}} \pm 0.001$ & $0.06^{\mathrm{B}} \pm 0.001$ \\
10th & $0.17 \pm 0.002$ & - & $0.02^{2} \pm 0.001$ \\
11th & $0.10 \pm 0.001$ & & \\
12th & $0.03 \pm 0.001$ & & \\
\hline
\end{tabular}

Based on a detailed analysis of changes in milk yields the conclusion was drawn that sheep of $\mathrm{G}$ I on the 10th day of milking (first control milking) produced the significantly $(P \leq 0.05)$ highest amount of milk at the level of $0.48 \pm 0.018$ litres of milk daily (Table 2). The least milk was obtained from sheep of G II and G III ( $0.42 \pm 0.008$ and $0.43 \pm 0.013$ litres of milk daily respectively). During the second experiment milk yield in sheep from $\mathrm{G} \mathrm{I}$ amounted to $0.45 \pm 0.017$ litre of milk daily and was higher $(P \leq 0.05)$ than milk yields of sheep of G II and G III $(0.40 \pm 0.016$ and $0.33 \pm 0,009$ litres of milk daily). On the 30th day of milking (third control milking) the milk yield in sheep of $\mathrm{G} \mathrm{I}$ amounted to $0.50 \pm 0.012$ litres of milk daily and was significantly $(P \leq 0.01)$ higher than milk yields of sheep of $\mathrm{G} \mathrm{III}(0.28 \pm 0.001$ litres of milk daily) and was higher $(P \leq 0.05)$ than milk yields of sheep of $G$ II $(0.38 \pm 0.012$ litres of milk daily). During 10 consecutive days of milking sheep of $\mathrm{G}$ I still produced the highest milk yields $(0.45 \pm 0.011$ litres of milk daily). Significantly $(P \leq 0.01)$ lower milk yields were observed in sheep of $\mathrm{G} \mathrm{III}(0.26 \pm 0.001$ litres of milk daily) and was higher $(P \leq 0.05)$ than milk yields of sheep of $\mathrm{G} I \mathrm{l}(0.35 \pm 0.015$ litres of milk daily). In the fifth control milking sheep of G I produced $0.37 \pm 0.012$ litres of milk daily. Sheep of G II and G III, in 
turn, produced significantly $(P \leq 0.05)$ lesser milk $(0.30 \pm 0.001$ and $0.23 \pm 0.015$ litres of milk daily respectively). As lactation progressed, milk yields dropped both in sheep entering lactation in the long-day period (G I) and in sheep milked in the period of shorter days and exposed to the effects of exogenous MLT (G II, G III). On the 70th day of milking (seventh control milking) the milk yield in sheep of $\mathrm{G} I$ amounted to $0.37 \pm 0.006$ litres of milk daily and was significantly $(P \leq 0.01)$ higher than milk yields of sheep of $\mathrm{G} I \mathrm{I}$ and $\mathrm{G}$ III $(0.18 \pm 0.001$ and $0.14 \pm 0.012$ litres of milk daily). The significantly $(P \leq 0.01)$ highest milk yields, though, were recorded in sheep of $G$ I $(0.26 \pm 0.006$ litres of milk daily), whereas mothers in G II and III produced as little as $(0.15 \pm 0.002$ and $0.07 \pm 0.009$ litres of milk daily). During 10 consecutive days of milking sheep of $G$ I produced significantly $(P \leq 0.01)$ more milk reaching the level of $0.20 \pm 0.009$ litres of milk daily, whereas sheep entering lactation in the period of shorter days, G II, produced $0.02 \pm 0.001$ litres of milk daily and G III sheep yielded $0.06 \pm 0.001$ litres of milk daily. During the 10 th control milking the milk yield in sheep of $\mathrm{G}$ I amounted to $0.17 \pm 0.002$ litres of milk daily and milk yields of sheep of G II and G III were $0.02 \pm 0.001$ litres of milk daily.

\section{Secretion of melatonin}

An analysis of the concentration of MLT in sheep of G I milked in the long-day period revealed that the concentration of MLT was significantly $(P<0.05)$ lowest in April and May $(77.8 \pm 8.9 \mathrm{pg} / \mathrm{ml}, 73.3 \pm 6.3 \mathrm{pg} / \mathrm{ml}$ respectively) (Figure 1). As lactation progressed and days became shorter, the concentration of MLT increased and in June $(91.3 \pm 6.4 \mathrm{pg} / \mathrm{ml})$ and July $(124.7 \pm 10.1 \mathrm{pg} / \mathrm{ml})$ it was significantly $(P \leq 0.05)$ higher compared to previous drawn samples. In August secretion of MLT increased reaching the level of $132.8 \pm 16.1 \mathrm{pg} / \mathrm{ml}$. In the last month of milking, September, the concentration of MLT amounted to $133.5 \pm 16.4 \mathrm{pg} / \mathrm{ml}$. In sheep of $\mathrm{G} \mathrm{II}$, which were milked in the period of shorter days, in August the concentration of MLT

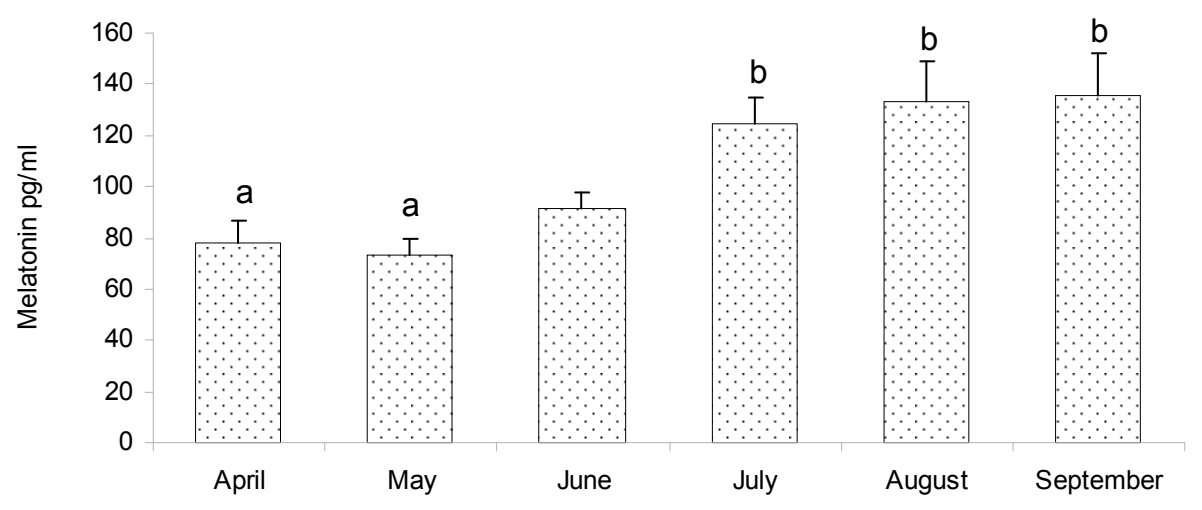

$\varpi$ Group I

Months

Figure 1

Mean ( \pm SEM) plasma melatonin hormone sheep kept under natural lighting conditions (Group I)

${ }^{\mathrm{ABC}}$ means in months denoted with the different letters differ significantly at $P \leq 0.01$, abmeans in months denoted with the different letters differ significantly at $P \leq 0.05$. See text for statistical comparisons. 
in the first month of milking equalled $22.44 \pm 8.75 \mathrm{pg} / \mathrm{ml}$. In G III, in turn, the concentration of this hormone was $106.46 \pm 10.7 \mathrm{pg} / \mathrm{ml}$ and differences were statistically significant $(P \leq 0.001)$ (Fig 2). In the second month of milking (September) the concentration of MLT in G II reached the level of $23.97 \pm 8.86 \mathrm{pg} / \mathrm{ml}$ and in G III it amounted to $97.16 \pm 10.7 \mathrm{pg} / \mathrm{ml}$, whereas differences were statistically significant $(P \leq 0.001)$. In October, on the 90 th day of milking, the concentration of MLT in G II was at the level of $48.56 \pm 8.7 \mathrm{pg} / \mathrm{ml}$, whereas in $\mathrm{G}$ III it amounted to $92.93 \pm 10.8 \mathrm{pg} / \mathrm{ml}$ with significant differences $(P \leq 0.001)$. In the last drawn sample, in November, in G II the concentration of MLT amounted to $67.68 \pm 8.7 \mathrm{pg} / \mathrm{ml}$ and in the $\mathrm{G}$ with MLT implants it reached the level of $71.31 \pm 10.6 \mathrm{pg} / \mathrm{ml}$.

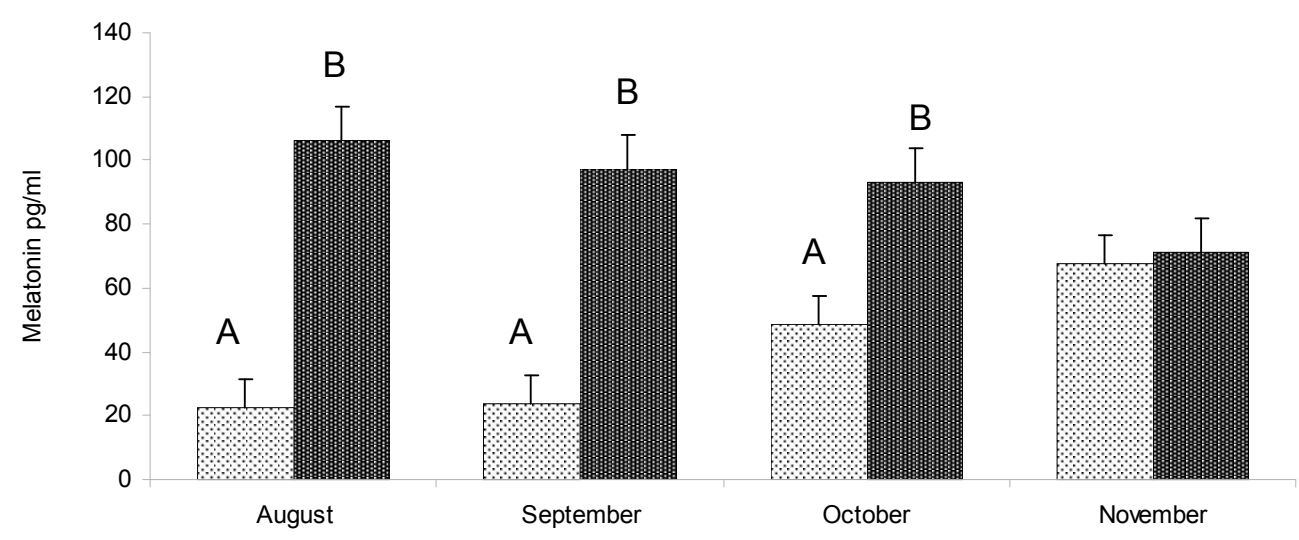

圈 Group II 䀦 Group III

Months

Figure 2

Mean ( \pm SEM) plasma melatonin hormone sheep kept under natural lighting conditions (Group II) and sheep with exogenous melatonin implants (Group III)

${ }^{A B C}$ means in months denoted with the different letters differ significantly at $P \leq 0.01,{ }^{a b}$ means in months denoted with the different letters differ significantly at $P \leq 0.05$, See text for statistical comparisons.

\section{Discussion}

In sheep, seasonal changes in secretion of MLT which are determined by the biological clock represent a signal in the annual reproductive cycle (Sweeney et al. 1999). The endocrine mechanism of entering and maintenance of lactation has not been fully understood. Despite that, it involves a great number of hormones, which proves that the process relies basically on the activity of hypothalamus and pituitary gland (Morgan 1996, 2000).

The present studies demonstrated that the introduction of exogenous MLT six weeks before lambing significantly decreased the sheep's milk yields in the first $28 \mathrm{~d}$ after rearing of lambs. At this time an increased level of secretion of MLT, which is a hormone inhibiting secretion of prolactin, did not cause a drop in milk secretion. Studies carried out by Misztal et al. 2008 and Górski et al. 2009 showed that the sucking factor, i.e. stimulation of the udder, gives rise to increased secretion of prolactin and growth hormone. In the milking period the longest lactation and the highest milk yields were observed in sheep milked in the long- 
day period. In these sheep MLT retained the features of the seasonal rhythm, i.e. a low level in the long-day period and a high level in the autumn and winter period. Sheep milked in the short-day period, in turn, had worse milk-performance parameters. The results of the studies conducted by Molik et al. 2007 demonstrated that a shift of the lactation period to the period of shorter days had a negative effect on milk-performance parameters of seasonally breeding sheep. Increased secretion of MLT in the period of shorter days contributed to lower milk secretion in sheep. The studies by Lincoln et al. $(1992,2000)$ and Misztal et al. (1999) carried out on barren sheep and rams demonstrated similar trends of the MLT profile. The milk-performance parameters in seasonally breeding sheep are undoubtedly affected by the profile of MLT which modulates secretion of lactothroph hormones. The conducted studies revealed that in sheep of G II the concentration of MLT started to increase from the very beginning of milking and corresponded with the endogenous rhythm. Milk yields in the first month of milking were significantly lower than those in sheep of $\mathrm{G} I$. The duration of lactation and milk yields in sheep of G II were significantly lower.

The introduction of MLT implants during high pregnancy (six weeks before lambing) caused a drop of milk secretion from the very first days of milking, but the sheep had longer lactation than G II sheep. The data of milk yields between G II and III seem to be very interesting; in G III a lower milk yield was observed compared to G II. As a result of MLT implant insertion in a period of six weeks before parturition a decrease in milk field was noted. Study herein showed that introduction of exogenous MLT during the long-day period (May) did not created the state of MLT resistance during the short days and did not let maintain the milk field when day was shortened. At the beginning of the study we posted the hypothesis that introduction of the short day signal during pregnancy allow us to create the state of MLT resistance (from August till November) and would not lead to the decrease in milk yield.

The performed studies provided new information about the possibility of modulating milk secretion in sheep. The obtained results demonstrated that the introduction of a shortday signal by inserting MLT implants six weeks before lambing did not reduce the effect of the so called MLT resistance in the short-day period. Even the sucking factor in the period of lambs rearing did not overcome the inhibitory effect of MLT on the secretion of prolactin.

\section{Acknowledegements}

This project was supported by a grant from the Polish National Research Council (N N 311 245033 MNiSzW).

\section{References}

Arendt J, Symons AM, English J, Poulton AL, Tobler I (1988) How does melatonin control seasonal reproductive cycles? Reprod Nutr Dev 28, 387-397

Dahl GE, Buchanan BA, Tucker HA (2000) Photoperiodic Effects on Dairy Cattle: A Review. J Dairy Sci 83, 885-893

Fraser S, Cowen P, Franklin M, Franey C, Arendt J (1983) Direct Radioimmunoassay for Melatonin in Plasma. Clin Chem 29, 396-397

Górski K, Romanowicz K, Herman A, Molik E, Gajewska A, Tomaszewska-Zaremba D, Misztal T (2009) The Possible Involvement of Salsolinol and Hypothalamic Prolactin in the Central Regulatory Processes in Ewes During Lactation. Reprod Domest Anim, e54-e60 
Karsch FJ, Bittman EL, Foster DL, Goodman RL, Legan SJ, Robinson JE (1984) Neuroendocrine basic of seasonal reproduction. Recent Prog Horm Res 40,185-232

Lincoln GA, Maeda KI (1992) Effects of placing micro-implants of melatonin in the mediobasal hypothalamus and preoptic area on the secretion of prolactin and $\beta$-endorphin in rams. J Endocrinol 134, 437-448

Lincoln GA, Clarke IJ (2000) Role of the Pituitary Gland in the Development of Photorefractoriness and Generation of Long-Term Changes in Prolactin Secretion in Rams. Biol Reprod 62, 432-438

Lincoln GA, Andersson H, Clarke IJ (2003) Prolactin Cycles in Sheep under Constant Photoperiod: Evidence That Photorefractoriness Develops Within the Pituitary Gland Independently of the Prolactin Output Signal. Biol Reprod 69, 1416-1423

Misztal T, Romanowicz K, Barcikowski B (1996) Seasonal changes of melatonin secretion in relation to the reproductive cycle in sheep. J Anim Feed Sci 5, 35-48

Misztal T, Romanowicz K, Barcikowski B (1999) Melatonin Modulation of the Daily Prolactin Secretion in Intact and Ovariectomized Ewes. Relation to a Phase of the Estrous Cycle and to the Presence of Estradiol. Neuroendocrinology 69, 105-112

Misztal T, Górski K, Tomaszewska-Zaremba D, Molik E, Romanowicz K (2008) Identification of salsolinol in the mediobasal hypothalamus of lactating ewes and its relation to suckling-induced prolactin and GH release. J Endocrinol 198, 83-89

Molik E, Misztal T, Romanowicz K, Wierzchoś E (2006) The influence of length day on melatonin and prolactin secretion during lactation in asesonal sheep. Arch Tierz 49, Special Issue, 359-364

Molik E, Misztal T, Romanowicz K, Wierzchoś E (2007) Dependence of the lactation duration and efficiency on the season of lambing in relation to the prolactin and melatonin secretion in ewes. Livest Sci 107, 220-226

Molik E, Misztal T, Romanowicz K, Zięba D, Wierzchoś E (2009) Changes in growth hormone and prolactin secretions in ewes used for milk under different photoperiodic conditions. Bull Vet Inst Pulawy 53, 389-393

Molik E, Misztal T, Romanowicz K, Zieba DA (2010) The effects of melatonin on prolactin and growth hormone secretion in ewes under different photoperiods, during the early post partum period. Small Rumin Res 94 , 137-141

Molik E, Bonczar G, Żebrowska A, Misztal T, Pustkowiak H, Zięba D (2011) Effect of day length and exogenous melatonin on chemical composition of sheep milk. Arch Tierz 54, 177-187

Molik E, Misztal T, Romanowicz K, Zieba D (2013) Short-day and melatonin effects on milking parameters, prolactin profiles and growth-hormone secretion in lactating sheep. Small Rumin Res 109, 182-187

Morgan PJ, Williams LM (1996) The pars tuberalis of the pituitary: a gateway for neuroendocrine output. Rev Reprod 1,153-161

Morgan PJ (2000) The Pars Tuberalis: The Missing Link in the Photoperiodic Regulation of Prolactin Secretion? J Neuroendocrinol 12, 287-295

Morrissey AD, Cameron AWN, Tilbrook AJ (2008) Artificial Lighting During Winter Increases Milk Yield in Dairy Ewes. J Dairy Sci 91, 4238-4243

Norms (1993) [Nutrient requirements for cattle and sheep in the traditional system]. 6th rev. ed. IZ Krakow, Poland [in Polish]

Peters RR, Chapin LT, Leining KB, Tucker HA (1978) Supplemental lighting stimulates growth and lactation in cattle. Science 199, 911-912

Reiter RJ (1991) Melatonin: That Ubiquitously Acting Pineal Hormone. Physiology 6, 223-227

Reksen O, Tverdal A, Landsverk K, Kommisrud E, Bøe KE, Ropstad E (1999) Effects of Photointensity and Photoperiod on Milk Yield and Reproductive Performance of Norwegian Red Cattle. J Dairy Sci 82, 810-816

Russel AJF, Doney JM, Gunn RG (1969) Subjective assessment of body fat in live sheep. J Agric Sci 72, 451-454

Sweeney T, Kelly G, O'Callaghan D (1999) Seasonal Variation in Long-Day Stimulation of Prolactin Secretion in Ewes. Biol Reprod 60, 128-133 